VTT, tutkija Jaana Lähteenmaa, HY, Taloustieteen laitos jaana.lahteenmaa@helsinki.fi

\title{
Erityyppiset maaseudut nuorten kotipaikkoina - vertaileva näkökulma
}

Suomalainen maaseutu elää, taas, murrosten kourissa. Sen lisäksi, että jo 60-luvulta asti tuttu syrjäseutujen tyhjeneminen vielä paikoin jatkuu, pienteollisuus, palveluelinkeinot yms. korvaavat perinteistä maaseutumaista elinkeinovalikoimaa yhä enemmän elinvoimaisemmalla maaseudulla. Lisäksi suurten kaupunkien ympärille virkoaa ns. pendelöintimaaseutua. Täten ei ole mielekästä puhua vain yhden tyyppisesestä maaseudusta nuorten kotiseutuna. Maan sisäistä vertailua maaseudusta nuorten kasvuynpäristönä ei ole aiemmin Suomessa tehty. Omassa tutkimuksessani (Lähteenmaa 2006, 2007) pyrin tekemään tällaista vertailua, tosin kavlitatiivsiella aineistolla ja eräänlaislla " tapaustutkimuksilla” .

Olen jakanut maaseudun karkeasti kolmeen tyyppin: elinvoimainen, kituva ja kasvava maaseutu. Näiltä kolmelta erityyppiseltä maaseudulta olen kerännyt essee-kirjoituksia 13-16vuotiaalta; kotiseututuntumuksia ja - ajatuksia sekä poismuutto- vs. jäämishaluja haarukoiden. Tulkintakehikkonani on rakentamani kahden akselin malli: siinä sekä kotipaikan (oletettu) tulevaisuus että oletettu mennisyys ovat ikään kuin "muuttujia”, jotka voivat saada eri "arvoja" - abstraktissa, ei kvantitatiivsiessa mielessä. Oletukseni mukaan, erityyppisten maaseutujen nuoret asukkaat sijoittuvat tulevaisuus- ja menneisyysvisioineen akseliston eri "kohtiin".

Ensimmäinen "akseli” on " suhde kotipaikan menneisyyteen", toinen taas "suhde kotipaikan oletetttun tulevaisuuteen". Esseistä piirtyvän kuvan mukaan näyttää siltä, että elivoimaisella maaseudulla sekä suhde kotipaikan (oletettuun) menneisyyteen - siis paikallistraditioihin, kunnan taannoisiin suurmiehiin (ja - naisiin) jne. - on elävä, ja jopa paikkalisylpeyden lähde. Suhde kunnan oletettuun tulevaisuuteen on - faktoihin nähden - jopa "ylioptimistinen": kotipaikan oletetaan mm. kasvavan tulevaisuudessakin vauhdilla, joka ei tilastojen yms. valossa ole täysin realistinen.

Ns. pendelöintimaaseudulla suhde kotipaikan oletettuun tulevaisuuteen on niinikään optimistinen - mikä vastannee realiteetteja, ainakin luvassa olevan kasvun osalta. Mutta suhde kotipaikan menneisyyteenkin on vahva, vaikka monet nuoret ovat 1 . polven paikkakuntalaisia. ”Kotiseutuhenkeä” löytyy silti paljon. Tämä viittaa siihen, että optimistiset tulevaisuduenvisiot ruokkivat myönteistä menneisyyssuhdetta. Kitvulla, tyhjenevällä maaseudulla molemmat nämä suhteet ovat varsin kielteisiä. Vaikka kotipaikalla onkin menneisyyttä, siitä ei puhuta. Yleinen tulevaisuuspessimismi heittää varjonsa myös menneisyyssuhteeseen: nuoret katsovat, että paikakkunassa ei ole juuri mitään, mistä voisi olla.

Ainoastaan mielikuva kotipaikan luonnon kauneudesta ja puhtaudesta ja oman elinympäristön ylivertaisuudesta kaupunkiin nähden tässä suhteessa yhdistää kaikentyyppisillä maaseuduilla asuvia nuoria. Näin ollen ei voida puhua yhdentyyppisesetä nuoruudesta suomalaisella maaseudulla, eikä vain yhdestä "maaseutunuorten kotipaikka-identiteetistä." 


\section{Johdanto}

Hypoteesini mukaan erityyppisillä maaseuduilla (perinteinen elinvoimainen maaseutu; pendelöinti-maaseutu tai ns. asuinmaaseutu (ks. Mäkelä 2006); sekä kuihtuva syrjämaaseutu) elävät nuoret rakentavat kotipaikka-identiteettiänsä toisistaan poikkeavilla tavoilla. Esiymmärrykseni mukaan kotipaikka-identiteettien rakentamisessa ovat mukana niin nuoren suhde kotipaikkansa (oletettuun) menneisyyteen kuin suhde sen (oletettuun) näköpiirissä olevaan tulevaisuuteenkin, ainakin jossain määrin relevantteina elementteinä. Mutta mikä on niiden keskinäinen suhde tai vuorovaikutus kuvatussa kotipaikkasuhteessa - siitä minulla ei ollut tutkimuksessani ennakko-olettamusta.

\section{Empiirinen aineisto ja analyysi}

Empiirisenä materiaalina tutkimuksessani on on kolmelta erityyppilseltä paikakkunnalta olevien 14-16- vuotiaiden nuorten kirjoittamat esseet, jotka liittyvät heidän kotipaikkaansa tai heidän suhteeseensa siihen.Esseet kirjotietettiin kouluaikana. Vaihtoehtoisia, muotoilemiani otsikoita aiheenseen liittyyen oli tarjolla yhteensä 8 (ks. niistä tarkemmin Lähteenmaa 2006; 2007). Nuoret kirjoittajat olivat Pohjanmaalla sijaitsevalta hyvinvoivalta ja kulttuurisesti vireältä maaseutupaikkakkunnalta - kutsun sitä jatkossa "Viilukkaaksi”-, pohjoissavolaiselta, väestötappiosta jo pitkään kärsineeltä entiseltä metsätyövaltaiselta paikkakunnalta, jota kutsun jatkossa ”Jalokoksi”, sekä Uudellamaalla sijaitsevalta, väestöllisesti kasvavalta ns. pendelöintimaaseutupaikkakunnalta, jota kutsun jatkossa "Kuuraiseksi”. Yhteensä esseitä kirjoitettiin 101 kappaletta.

Analyysieni metodologisena lähtökohtana on sosiaalinen konstruktionismi: oletan, että nuoret kuvaavat teksteissään kotipaikkaansa ja/tai suhdettaan siihen rakentaen samalla ainakin itselleen merkityksellistä näkökulmaa asiaan. Puhuvatko he "totta” vai eivät ei ole relevantti kysymys - olennaista on, että he kertoavat asiasta tavalla, joka on heille itselleen mielekäs, ja myös mahdollinen. Se, miten kotipaikastaan on mahdollista kertoa, kietoutuu jossain määrin myös realiteetteihin, jotka asettavat kerronnalle eräänlaisia reunaehtoja.

Analysoin esseet ns. palvikorttimenttelmällä, teemoittain. Analyysin kannalta relevantit teemat olivat osittain mielessäni jo etukäteen, osa muotoutui analyysia tehdessäni. Teemojen tarkasteluun sain tulkinnallista tukea myös asiaan liittyvästä aiemmasta tutkimuksesta, mm. Malmstenin luokittelusta (2004) koskien suomalaisessa julkisuudessa esiintyviä maaseutumielikuvia. Teorettista inspiriaatiota aineiston analyysiin hain myös Somersin (1994) hahmottamasta narratiivisen identiteetin eräänlaisten "rakennuselementtien” tyypittelystä.

\section{Tulokset ja niiden tarkastelu}

Nopeasti kasvavalla pendelöinti-maaseudulla nuoret käyttivät kotiapikkakuvauksissaan yllättävän paljon "maaseutu myönteisellä tavalla muuttumattomana” - disksurssin (ks. Malmsten 2004) elementtejä ylistäessään kotipaikkansa luontoa, hiljaisuutta, jne. Myös vauraalla, perinteikkäällä maaseudulla (kunta Pohjanmaalla) käytettiin samaa puhetapaa 
runsaasti. Näissä paikoissa nuoret kirjoittivat kotipaikoistaan varsin vähän täysin kielteisiä tekstejä; myönteisten lisäksi esiintyi pohtivia tai monia kotipaikan eri puolia esiin ottavia tekstejä.

Sen sijaan väestömäärältään ja taloudeltaan pitkään taanntuneessa paikassa Savossa myönteisten kirjoitusten - jotka niinikään liittyivät luonnon kauneuden ylistämiseen, hiljaisuuteen, yms:een - rinnalla esiintyi runsaasti erittäin kielteisiä tekstejä. Kielteisyys liittyi tyypillisesti paikan köytymiseen, väestömäärän vähenemiseen, paikan pienuuteen , syrjäisyyteen ja sen elinmahdollisuuksien tukahtumiseen. Kuvailtiin myös sitä, miten karmeata on ollut syntyä tällaiselle paikkakunnalle.

Myönteisyys- kielteisyys - ero tuli voimakkaimmin esille kotipaikan tulevaisuutta koskevissa teksteissä. Sekä Uudellamaalla että Pohjanmaalla sijaitsevissa kunnissa, "Kuuraisessa” ja "Viilukkaassa" nuoret näkivät kotiapikkansa tulevaisuuden valoisana, kasvun ja lisääntyvän hyvinvoinnin sävyttämänä. Pohjalaispaikkakunnan nuoret "näkivät" sellaistakin kasvua, joa ei ole kovin todennäköistä realiteettien valossa. Sen sijaan savoalispaikkakunnan, "Jalokon", nuoret maalailivat varsin synkkiä tulevaisuuden visioita, joilla - jo tapahtuneen ja luultavasti jatkuvan kehityksen valossa - on tietty realiteettipohja, mutta jotka synkkyydessään ja lohduttomuudessaan saivat suorastaan traagisia mittasuhteita. ” Koko tämä paikka katoaa Suomen kartalta, kohta tätä ei edes muista kukaan... vain musta kissa hiippailee raunioissa..." - ja niin edelleen.

Nuorille kirjoittajille tärkeänä teemana, jota ei ollut otsikossa tarjottu, nousi esiin käsitykset ja pohdinnat siitä, millainen maine, ”imago”, kotipaikkakunnalla on.

Ääripäinä erottouivat pohjalaispaikkakunta, jonka maineesta - etenkin kansanmusiikkikuntana - ilmaistiin iloa ja ylpeyttä, ja toisaalta tyhjenevä syrjäseutupaikkakunta, jonka oletetusta maineesta nuoret olivat lähinnä huolissaan tai pahoillaan. Tämä oletus on tiivistettävissä yhden nuoren mutoiluun ”Jos joku tästä paikasta ylipäätään jotain tietää, niin varmastikin pelkkää pahaa." Pendelöintipaikkakunnalla nuoret eivät näyttäneet olevan niin kiinnostuneita kotipaikkansa maineesta, mutta sikäli kun siitä joitain käsityksiä ilmasitiin, ne olivat pääosin myönteisiä.

Yllättävää kyllä, kovaa vauhtia kasvavan pendelöintipaikkakunnan nuorten esseissä useammassa kuin yhdessä - viitattiin myös paikkakunnan menneisyyteen, siellä taannoin vaikuttaneeseen "suurmieheen” . Muuttotappiopaikkakunnan nuorista kukaan ei viitannut paikkakuntansa menneisyyteen tai traditioihin sanallakaan. Kulttuurielämältään vireän pohjalaispaikkakunnan nuorista melko monet viittasivat paikkakunnan elävään traditioon, kansanmusiikkiin. Tekemissäni taustahaastatteluissa tuli esiin, että kasvavalla pendelöinti-paikakkunnallla koulussa oli eritoten panostettu paikkakunnan taannoiseen suurmieheen perehtymiseen- näemmä toivotuin tuloksin.

Kun Malmsten (2004) hahmottaa kaksi neljästä median maaseutukuva-tyypistä kielteiseksi, toista kielteisesetä maaseutukuvatyypistä - "maaseutu muuttumattomana kieteisessä mielessä" - ei löytynyt nuorten kuvastosta ollenkaan. Kileteinen maaseutukuva, toinen niistä, oli löydettävissä pelkästään tyhjenevän syrjäseutupaikkaunnan nuorten teksteistä: se liittyi Malmstenin kuvaamista tyypeistä "maaseutuu muuttuvana - eli tyhjenevänä ja taantuvana - kielteisessä mielessä" kuvaan. 


\section{Johtopäätökset}

$\mathrm{Ne}$ elementit, joista nuoret rakentavat kotipaikka-identiteettiään suomalaisella maaseudulla, eroavat huomattavasti toisistaan erityyppisillä maaseuduilla. Toisaalta yksi yhteinenkin elementti näyttää löytyvän: se on maaseudun luonnon, hiljaisuuden, rauhan ja turvallisuuden ylistäminen. Tämä tulee lähelle Malmestenin hahmotuksen (mt.) "maaseutu muuttumattomana myönteseillä tavalla”- diskurssia. Sen näyttävät siis jakavan jotakuinkin kaikki - ainakin tämän tutkimuksen piirissä olevat - maaseudun nuoret.

Suurimmat erot erityyppisten maaseutujen nuorten kotipaikka-identiteeteissä tulivat esiin kotipaikkojen tulevaisuutta koskevissa eistetyissä näkemyksissä sekä pohdinnoissa koskien oman kotipaikan "julkista kuvaa”. Tuelvaisuutta koskevilla esitetyillä visioinneilla oli tietty yhteytensä kotipaikkojen realiteteetteihin, mutta ei kuitenkaan täysin. Esimerkiksi pohjalaispakkakunnalla ,"Viilukkaassa", nuoret uumoilivat kotikuntansa voimakasta kasvua, vaikka sellaisesta ei näkynyt tutkimushetkellä juuri merkkejä - jos kohta ei paikan taantumisestakaan.

Suomalaista maaseutua on todellakin monenlaista; myös nuoren kasvuympäristönä erityyppiset maaseutukunnat poikkeavat siis huomattavasti toisistaan. Vaikka maaseudun nuoria ja maaseutua nuorten elinympäristönä on viime vuosina tutkittu Suomessa (esim. Tuhkunen 2002; Jukarainen ja Tuhkunen 2004) Pohjoismaissa (esim. Helve (toim.) 2003) ja maailmallakin (esim. Bushin et al. 2007) , maaseudun nuorten elinympäristöjen ja paikallis-identiteettien rakentumisen eroihin erityyppisllä maaseuduilla , varsinkaan yhdesaä ja samassa maassa, ei ole kiinnitetty huomiota.

Tässä tutkimuksessa esiin tulleet erot erityyppisissä maaseuduissa nuorten kasvuympäristöinä liittyvät pitkälti rakenteellisiin ja sijainnillisiin tekijöihin, mutta erityyppisten maaseutupaikkakuntien väliset ilmapiirierotkin ovat ilmeisesti huomattavan suuria. Tosin näillä ilmapiireillä näyttää olevan yhteytensä realiteteetteihin, mutta taas kerran: ei kutienkaan aivan 1:1:een logiikalla. Lisäksi paikkakunnan ilmapiiri on omiaan vaikuttamaan myös sen realiteteetteihin - siihen, millaisessa hengessä kuntaa kehitetään tai ollaan kehittämättä, miten paljon sieltä lähdetään tai ollaan lähtemättä. Etenkin nuorten poislähtemiseen ilmapiiriin optimistisuuden vs. pessimistisyyden voi olettaa vaikuttavan erityisen voimakkaasti.

Hypoteesi, jonka olin asettanut tutkimuksen alussa, sekä saa tukea että tarkentuu empiirisen analyysini valossa. Paikallis-identiteetin rakentamisen kannalta tärkeiksi uumoilemani "akselit” - sekä suhde paikakkunnan oletettuun tulevaisuuteen että sen oletettuun menneisyyteen ja traditioihin - näyttävät olevan nuorille relevantteja, kun he kirjoittavat kotipaikoistaan. Mutta näiden "akseleiden” välinen suhde on mutkikkaampi kuin mitä olin saonnut olettaa ennakolta. Ne molemmat vaikuttvat toisiinsa, mutta vielä niin, että tulevaisuus- akselilla on yllättävän suuri merkitys myös sille, millaiseksi menneisyys- akseli muodostuu.

Ilmeisesti on niin, että kun kotipaikan oletettu tulevaisuus näyttää, ihmisten silmissä, varsin synkeältä, myös kuva oletetusta menneisyydestä sekä paikallistraditioista himmenee tai häipyy näköpiiristä (näin näyttää käyneen tämän analyysin paikkakunnista väestökatoa jo pitkään poteneessa syrjäseutupaikassa ”Jalokossa”) . Ja taas toisaalta: kun käsitys paikkakunnan tulevaisuudesta on valoisa, myös menneisyydessä, lähes yrittämällä yrittäen, nähdään jotain hyvää ja erityisen arvokasta (kuten tutkimuksen paikkakunnista pendelöinti-kunta "Kuuraisen” tapauksessa). 
Ja toisinpäin: kun menneisyys nähdään arvokkaana ja paikallis-traditiot ovat elinvoimaisia nuortenkin piirissä, myös kotipaikan tulevaisuus nähdään valoisana - jopa (todennäköisesti) epärealistisessa määrin (kuten pohjalaispaikkakunta "Viilukkaan” tapauksessa.)

Jos katsomme nuorten paikallis-identiteetin rakentumista Somersin narratiivisen identiteetin rakennuselementtejä koskevan jaottelun näkökulmasta, varsinkin institutionaalisen elementin vahvuudessa on suuria paikkakuntatyyppeihin liittyviä eroja. (Somersin jaottelussahan on neljä eri rakenne-elementin tyyppiä: institutionaaliset; ontologiset; "suuriin kertomuksiin” kietoutuvat sekä julkisiin diskursseihin kieoutuvat, ks. Somers 1994, 605-649). Insitutionaalinen elementti näyttää olevan suhteellisen vahva sekä pohjalaispaikkakunta "Viilukkaassa” - jossa nuoret viittaavat paljon paikalliseen kansanmusiikkiperinteeseen ja siihen kietoutuviin insitituutioihin - että hieman yllättäen myös nopeasti kasvavavassa ja muuttuvassa pendelöinti-paikakkunta "Kuuraisessa": sen nuoret ovat yllättävän tietoisia ha halukkaita kertomaan paikakunnan menneisyyden varsinkin yhdestä, jo insitutionalisoituneesta tunnetusta hahmosta. Sen sijaan monien ongelmien kanssa kamppalaivessa syrjäseutukunnassa, "Jalokossa", nuoret eivät kirjoituksissaan viittaa juuri mihinkään paikallisiin instituuioihin- ainakaan myönteisessä sävyssä.

Jos "maaseudun tyhjeneminen" on, ei vain vain yksi julkinen maaseutua koskeva diskurssi, vaan myös "suuri kertomus", tyhjenevän ”Jalokon" nuoret käyttävät siis voimallisesti yhtä tiettyä suurta kertomusta - sitä - paikallis-identiteettiään rakentaessaan. Heidän kotipaikkansa kannalta se on kuitenkin varsin pessimistinen "kertomus". Muita julkisia (public) narratiivisen identiteetin rakentamisen elementtejä käyttävät sen sijaan kaikki kirjoittavat nuoret jossain määrin: yksi julksiuudessa vallitseva puhetapa maaseudusta (muuttumattoma rauhaisan luonnon tyyssijana, ks. Malmstenin luokittelu) on käytössä kaikkien paikakkuntatyyppien nuorilla.

Narratiivisen identiteetin ontologinen taso (ks. Somers mt.) on vaikein jäljitettävä - ja vaikemmin ymmärrettävissä. Jos se tämän tutkimusainieston tapauksessa liittyisi tietystä paikasta kotoisin olemisen ja siellä elämisen kokemukselliseen ulottuvuuteen, sitä esiintyy kaikkien paikkakuntatyyppien nuorilla. Tosin se on voimakkaasti eri tavoin värittynyttä - myönteisestä kielteiseen (syrjäseutupaikkakunta "Jalokon” ollessa kielteisimmässä päässä).

Kun paikallis-identitteetin rakentaminen suomalaisella maaseudulla varioi näinkin paljon kotipaikasta riippuen - tämän kietoutuessa voimakkaasti siihen, millaisella maaseututyypillä kotipaikka sijaitsee - en näe mielekkääksi puhua yleistävästi suomalaisesta "maalaisen" identiteetistä, ainakaan nuorten, tuskin aikuistenkaan kohdalla (vrt. Rosenqvist 2003). Erot näyttävät olevan ainakin nuorten kohdalla suurempia kuin yhidstävät tekijät, vaikka niitäkin on muutamia.

\section{Kirjallisuus}

Bushin, N., Ansell, N., Adrianssen, H., Lähteenmaa, J. \& Panelli, R. (2007): "Reflecting on contexts and identites for young rural lives”. Teoksessa Panelli, R. , Punch, S. \& 
Robson, E. (eds.): "Global perspectives on rural childhood and youth.: Young Rural Lives.” Routledge; New York.

Helve, Helena (toim.) (2003): Ung i utkant - aktuell forskning om geldsbygdungdomar i Norden. Nordiska ministerrådet, Kopenhagen.

Jukarainen, Pirjo ja Tuhkunen, Anne (2004): Imagosta identiteettiin - raja- ja syrjäseutujen nuorten muuttoliikeen lähtökohtia. Teoksessa Paju, Petri (toim.): "Samaan aikaan toisaalla... - Nuoret, alueellisuus ja hyvinvointi. " Nuorten elinolot- vuosikirja. Stakes, NuoRa \& Nuorisotutkimusverkosto, Helsinki. (sivut 94-105).

Lähteenmaa, Jaana (1996): Kotipaikka maaseudulla: nuorten näkökulmia idästä, lännestä ja etelästä. Teoksessa Wilska, Terhi- Anna \& Lähteenmaa, Jaana (toim.): "Kultainen nuoruus. Kurkistuksia nuorten hyvinvointiin ja sen tutkimiseen." Nuorisotutkimusverkosto ja Nuorisotutkimusseura, Verkkojulkaisusarja. Osoitteeessa www.nuorisotutkimusseura.fi/verkkojulkaisut.

Lähteenmaa, Jaana (1997): Home place in the countryside: exploring the views of young people living in three different locations in Finland. Teoksessa Muukkonen, Martti ja Sotkasiira, Tiina (toim.). "Youth at the crossroads." Karjalan tutkimuslaitoksen julkaisuja 1/2008, Joensuu.

Malmsten, Jarmo (2004): Maaseutu mediassa. Maaseudun Uusi Aika 1/2004, s.5-19.

Mäkelä, Matti (2006): ”Pankonpäällisen puolustus.” Maahenki Oy; Jyväskylä.

Rosenqvist, Olli (2003): Minä ja maaseutu - maallikkodiskurssit kriittisen maaseututkijan tulkitsemina. Maaseudun Uusi Aika 2/2003, s. 5-25.

Somers, Margaret R. (1994): The narrative constitution of identity: a relational network approach. Theory and Society 23 (5); s. 605-649.

Tuhkunen, Anne (2002): Ideal life and proud feelings of north: YOUNG - Nordic Journal of Touth Research, 10 (3-4), s. 42-60. 